\title{
MEASURING PARTICIPATION: A COMPARATIVE STUDY OF CITIZEN ENGAGEMENT PROCESSES IN URBAN PLANNING
}

\author{
JONE BELAUSTEGUIGOITIA ${ }^{1,2}$, IRATI ALONSO ${ }^{3}$, ANE CHUECA $^{3}$, ANE ELIZEGI $^{3}$, \\ SOFÍA HIERRO ${ }^{2}$, LUCÍA OLAVARRI ${ }^{2} \&$ ESTIBALIZ SANZ $^{4}$ \\ ${ }^{1}$ School of Architecture, The University of the Basque Country (UPV/EHU), Spain \\ ${ }^{2}$ Lur Studio, Spain \\ ${ }^{3}$ Createlli, Belgium \\ ${ }^{4}$ Basque Centre for Climate Change, BC3, Spain
}

\begin{abstract}
While there is a growing practice of engagement processes in urban planning, with diverse strategies and actions, there are still many questions regarding the evaluation; the gap being how to conclude that a process has been successful or not, and in what terms. In this context, this paper analyses a series of international reference models over the last fifty years, including levels of participation (Arnstein, UN-Habitat, IAP2), key performance indicators (IISD), evaluation guidelines (IOPD) and quality standards and indicators for community engagement (NSfCE, OGP, UNICEF). Based on this analysis, the research proposes an evaluative framework specific for citizen engagement in urban design and planning processes. The framework includes consists of six standards, with quantitative and qualitative indicators to consider both a process's outputs as its outcomes. The standards are: scope (level of engagement, process planning and structure), inclusion (diversity and quantity of stakeholders by gender, age, stake-holder type and others), mechanisms (typology, diversity and outreach), communication, building capacity (raising awareness and understanding), and impact (contribution to the urban plan). The research applies the framework to conduct a comparative study among cases of engagement processes in municipal-scale urban planning in the Basque Country, Navarre and Cantabria, in the north of Spain. Six case studies include small- and medium-sized towns and cities with a wide range in scale, from 4,000 to 350,000 people, and both pre-COVID and duringCOVID experiences. Results reveal tendencies, common benefits and challenges. Conclusions allow for a better understanding of the matter and expect to be useful and transferable to future urban planning-related engagement processes in order to overcome initial preconceptions, avoid false expectations, and better design and undertake them to increase their social impact and contribution to the urban plans they are framed within.
\end{abstract}

Keywords: citizen engagement, public participation, urban planning, inclusive urbanism.

\section{INTRODUCTION}

International and European standards for engagement in decision-making processes have evolved considerably in the last years, with numerous binding and non-binding documents reinforcing the notion that participation is a right that should be regulated and implemented, as well as existing good practices and benefits need to be highlighted and shared [1].

Diverse strategies and actions are used to a lower or higher extent of public participation, from basic information to full empowerment, including both digital and in person means. Regarding these last two, while technology provides economical and effective ways to engage citizens, when decision-making is required on large issues, there is no substitute for offline face-to-face engagement [2, pp. 7-8]. Consequently, engagement processes combine different actions or mechanisms in order to achieve their specific engagement goals.

Nevertheless, there are still many questions regarding the evaluation of these processes. According to Hanover Institute, standardization of public engagement evaluation and 
effective measurement approaches and tools are still in early stages, as it is difficult to quantify the impact of public engagement efforts, especially when they can comprise such a wide variety of initiatives. It is important to make a difference between process outputs and process outcomes and, although the evaluation of the first is more straightforward than the evaluation of the second, sophisticated evaluation methods tend to focus on the latter [3].

When it comes to urban planning, following this trend, there is a growing practice of engagement processes and similar lack of evaluation. In particular, the little research targeted on the use of co-design as a joint planning process between experts, the local community and stakeholders, suggests increased tendency of citizen awareness and understanding of urban development depending on the level of citizens' power in the process [4].

In this context, this paper focuses in the evaluation of citizen engagement processes specific to urban design and planning, addressing the question of how to conclude that a process has been successful or not, and in what terms; that is, according to what standards or criteria. The methodological approach begins with an analysis of engagement models and evaluative frameworks, to develop a specific one for urban design and planning, apply it in a series of case studies and extract conclusions to inform future practice.

\section{ANALYSIS OF INTERNATIONAL ENGAGEMENT MODELS}

\subsection{Reference engagement models analysed}

Over the last fifty years, since Arnstein's 1969 influential Ladder of Citizen Participation, different citizen engagement and public participation models have appeared worldwide. As democratic societies across the globe increasingly commit to collaborative governance, public participation has thereby emerged as a rich arena, including the "deliberative wave" that has gained ground since 2010 seeking ongoing, continuous and open dialogue and engagement between the public and public decision-makers [5]. Within the different existing engagement models, this paper analyses the following eight (Table 1): Arnstein's 1969 Ladder of Citizen Participation, UN-Habitat's 2007 Forms of Participation in an Urban Strategic Planning Process, the IAP2 Spectrum of Public Participation, the International Institute for Sustainable Development's (IISD) 2012 report on measuring community indicator systems, the International Observatory on Participatory Democracy (IOPD) 2013 Guide to Evaluate Participatory Processes, Scotland's 2016 National Standards for Community Engagement, the Open Government Partnership (OGP) 2017 Participation \& Co-Creation Standards, and UNICEF's 2019 Minimum Quality Standards and Indicators for Community Engagement.

Arnstein's 1969 Ladder of Citizen Participation [6] is considered one of the classic and most influential participation theories [7, p. 4]. Understanding citizen participation as a categorical term for citizen power, Arnstein proposes a provocative typology of eight levels of citizen participation based on the power relationship between what she refers to as the haves and the have-nots. Arranged in a ladder pattern (for illustrative purposes), the first two rungs relate to nonparticipation, being manipulation and therapy. Rungs 3, 4 and 5 are degrees of tokenism: informing, consultation and placation. At the top of the ladder, as degrees of citizen power, there is partnership, delegated power and citizen control. Arnstein describes each level, with specific examples, tools and caveats.

Within the notion of levels or degrees, and more related to urban planning, UN-Habitat presents seven Forms of Participation in an Urban Strategic Planning Process [8]: information, consultation, consensus building, decision-making, risk-sharing, partnership 


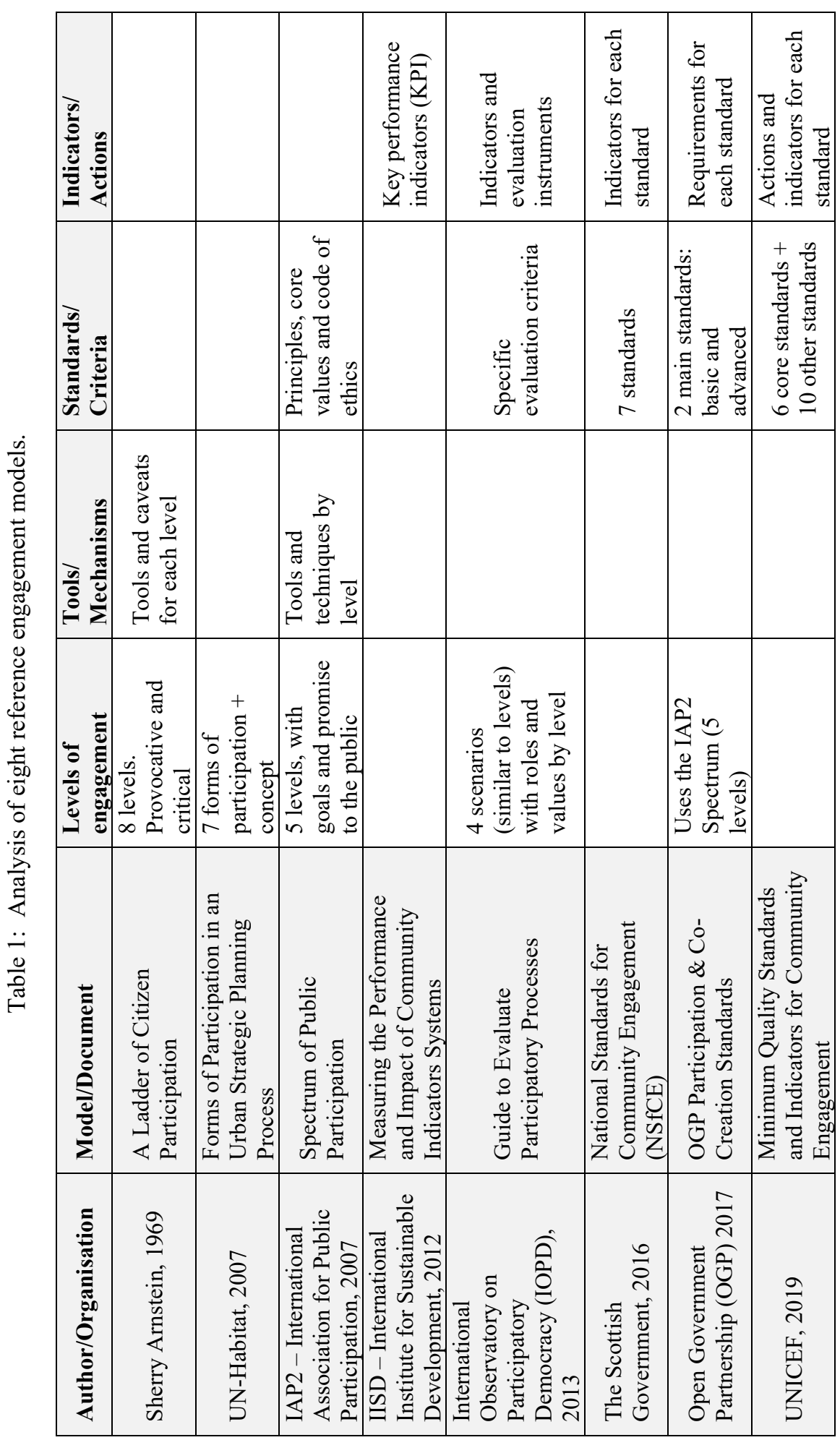


and self-management. These forms reflect three basic rights of citizens: the right to be informed (materialized through access to information), the right to be heard (materialized through consultations and consensus building), and the right to affect those activities which directly relate to people's living conditions (realized through inclusion in decision-making, risk sharing, partnership and self-management). Individual phases and stages call for different levels of participation and not all the stages require direct public participation. However, all these forms create a continuum, a gradual development of participation from the lowest- to the highest-intensity stages. UN-Habitat highlights urban consultation as the most important and effective means of stimulating participation and civic engagement in strategic planning. The framework describes each form of participation and when it occurs within the Urban Planning and Management Framework (UPMF).

In a similar way, also following this notion of levels, the IAP2 (International Association for Public Participation) provides its Spectrum of Public Participation [9], ranging from inform to consult, involve, collaborate and empower. The spectrum was developed to support and define the public's role in any public participation process. Essentially a matrix, it shows that differing levels are legitimate and depend on the goals, time frames, resources, and degrees of concern in the decision to be made, identifying the level to be chosen based on the specific goal of the project and the promise being made to the public. [7, p. 25]. The spectrum also includes example techniques or tools for each level. Moreover, the overall IAP2 framework provides Core Values, to define the expectations and aspirations of the public participation process, and a Code of Ethics on the actions of practitioners. It is widespread in North America, with different institutions following and adapting the spectrum to their specific realms (i.e., the US EPA for environment-related projects and the Facility Engagement for Canadian Medical Staff Associations, MSA). In 2009, together with the National Coalition for Dialogue \& Deliberation (NCDD), the Co-Intelligence Institute, and other leaders in public engagement, the IAP2 developed a series of seven Core Principles for Public Engagement: careful planning and preparation; inclusion and demographic diversity; collaboration and shared purpose; openness and learning; transparency and trust; impact and action; and sustained engagement and participatory culture [10].

Though not detailed in this paper, there are other models following a graduation of engagement, ranging from three to twelve levels. The European Center for Not-for-profit Law (ECNL) explains how the tools and mechanisms adopted by countries to implement and foster participation differ based on three main levels of engagement: information, consultation and active engagement through dialogue and partnership [1, p. 46]. On the other hand, Scott Davidson developed the Wheel of Participation for and with the South Lanarkshire Council to define and encourage levels of citizen participation for community planning and development. Based on four degrees (to inform, consult, participate and empower), the wheel presents, in all, twelve different levels, three in each degree [5, p. 8].

Shifting attention from engagement levels to specific evaluation tools, and though not an engagement model in itself, the International Institute for Sustainable Development's (IISD) 2012 report [11] provides a useful understanding on indicators as a tool for evaluation, reflection, learning and improvement. The report concludes a well-defined set of key performance indicators organized within a coherent evaluation framework can help Community Indicator Systems (CIS) to divide broad evaluation questions into more specific and manageable pieces, overcome vested interests and subjective biases, and provide hard empirical evidence of program performance and impact that can be used to engage stakeholders and to inform future planning and implementation. 
In this line towards support for evaluation, the International Observatory on Participatory Democracy (IOPD) developed in 2013 a Guide to Evaluate Participatory Processes [12]. Building from its previous 2006 guide and similar to the levels defined in the previously described models, the guide indicates four gradual participatory scenarios: information, communication (or dialogue), debate and decision. Additionally, it provides specific evaluation criteria, methodologies and indicators for five key areas: process coordination, participants, subject, method and consequences.

Responding to the need for standardization in evaluation mentioned in the introduction, Scotland's National Standards for Community Engagement (NSfCE) [13] are clear goodpractice principles designed to support and inform the process of community engagement, and improve the result. Originally launched in 2005 and revised 2015/2016, the standards provide detailed performance statements to achieve quality results and impact. The seven standards are: inclusion, support, planning, working together, methods, communication and impact. Each standard includes a short headline statement, a set of indicators to show progress towards meeting each standard, and some examples of good practice, within different sectors (health, social care, urban planning, budgeting, etc.). The National Standards are designed for public sector bodies and elected representatives, third sector organisations and community groups, and the private and independent sector. In this context, in 2017 the Scottish Government, together with Architecture \& Design Scotland and NHS Health Scotland, developed the Place Standard tool [14] to structure conversations to assess the quality of a place; be it well established, undergoing change, or still being planned. Viewed alongside digital engagement tools, the value of the Place Standard is how it facilitates face-to-face conversations [2, p. 4].

Likewise, the Open Government Partnership (OGP) published in 2017 its Participation $\&$ Co-Creation Standards [15]. The guidelines are based on evidence and experience and build on the IAP2 Core Values. The standards are divided into two overarching sections outlining basic requirements (the standard all countries are expected to meet) and advanced steps (the standard countries should strive for). Countries are expected to improve the quality of each cycle of the national OGP process, complying with more of the advanced steps outlined in these standards and moving from consult to collaborate on the IAP2 Spectrum. The standards are further organized around three essential elements of a participation and co-creation process: dissemination of information, spaces and platforms for dialogue and co-creation, and co-ownership and joint decision making.

Last within the analysed models, UNICEF presented in 2019 its Minimum Quality Standards and Indicators for Community Engagement [16]. Though specific for humanitarian assistance, the model is useful for other fields such as urban design and planning. Standards are organized into four sections to cover both core standards as well as support implementation, coordination and integration, and resource mobilization. Each standard includes quality criteria, detailing the minimum targets needed to achieve quality community engagement with a series of actions, listed as bullet points below each criterion. They are meant to be flexible and should be selected or adapted to local contexts as needed. The model also includes indicators, meant to trigger internal institutional review processes to study whether internal data collection, monitoring, evaluation, research, and learning tools and processes align with the community engagement minimum standards.

\subsection{Similarities, differences and gaps among the analysed models}

Many of the analysed models follow Arnstein's proposal of a gradient in participation, be it three levels (ECNL), four (IOPD), five (IAP2), seven (UN-Habitat), eight (Arnstein) or 
twelve (Davidson). Other than Arnstein's first two levels of nonparticipation, all analysed models place information at the basis for participation, followed by consultation. From there, names vary in a somewhat similar way referring to a higher intensity engagement level: involve, collaborate, consensus building, dialogue, debate, active engagement. Last, at the highest-intensity end of the range, models include: empower, decision-making, risksharing, partnership, self-management, delegated power and citizen control. The most notable difference in terms of levels is in the approach: while Arnstein provocatively refers to consultation as tokenism (a symbolic effort to be inclusive in order to give the appearance), the UN-Habitat highlights its importance and effectiveness. Except for Arnstein's, the rest of analysed models present the different levels legitimating them depending on the goals that are wished to be met.

All of these models present examples of engagement tools or mechanisms within each level, which is useful when designing a process, once the level of engagement is decided.

Some analysed models provide principles (IAP2) or quality standards and criteria (IOPD, NSfCE, OGP, UNICEF) to better design, plan and assess engagement processes. While each model has its own structure and uses different terms, there are similarities as to the areas the different standards cover. For instance, many refer to the process, as coordination (IOPD) and planning (NSfCE, UNICEF). Standards also relate to inclusion (NSfCE, UNICEF) and participants (IOPD); methods (IOPD, NSfCE), tools (IAP2) and activities (UNICEF); communication (NSfCE, UNICEF); and outcome, described as impact (NSfCE) and consequences (IOPD). Furthermore, some models provide indicators as a practical tool for evaluation (IISD, IOPD, NSfCE, OGP, UNICEF).

While these standards are flexible enough to be valid across different contexts and settings, they require to be fine-tuned in order to further apply them to the specific realm of urban design and planning. Citizen engagement in urban planning includes a variety of specific concepts and topics, and, at the same time, these are usually quite technical, thus, requiring an important effort to make them understandable to the general public. Moreover, it offers the opportunity for design-based methods typically used in the field, suitable to citizen engagement in the form of collaborative design or co-design methods between technicians (architects and planners), stakeholders and citizens, as "experts in experience".

\section{CITIZEN ENGAGEMENT EVALUATIVE FRAMEWORK FOR URBAN DESIGN AND PLANNING PROCESSES}

The proposed evaluative framework specific for citizen engagement in urban design and planning processes builds on the previous analysis. It consists of six standards, each relating to a specific goal and criteria and including a set of three main indicators to assess the extent to which the criteria are accomplished. Table 2 summarizes the six standards and indicators.

The first standard, scope, includes a first indicator on the level of engagement, targeted and achieved. Considering the different engagement models analysed, the framework uses the following four-level range: information, consultation, consensus building (which includes other models' levels of involve, dialogue, debate, collaborate, etc.) and decisionmaking (which includes partnership, self-management, empower, etc.). The second indicator relates to the process planning as some of the analysed models suggest. Last, the third indicator relates to the structure of the process by urban design and planning key topics (housing, public space, mobility, etc. included in Table 4).

The second standard, inclusion, looks at the targeted and participating stakeholder types and to participants' quantity as well as diversity by gender, age, stakeholder-type, location, family-work reconciliation and language. 
Table 2: Proposed evaluative framework for citizen engagement in urban planning.

\begin{tabular}{|c|c|}
\hline Standard & Indicators \\
\hline \multirow[t]{3}{*}{ 1. Scope } & 1.1 Level of engagement. \\
\hline & 1.2 Process planning. \\
\hline & 1.3 Structure by urban design and planning topics. \\
\hline \multirow[t]{3}{*}{ 2. Inclusion } & 2.1 Stakeholder types. \\
\hline & 2.2 Quantity of participants. \\
\hline & 2.3 Diversity of participants. \\
\hline \multirow[t]{3}{*}{ 3. Mechanisms } & 3.1 Typology of engagement mechanisms (by levels). \\
\hline & 3.2 Diversity of engagement mechanisms (by levels). \\
\hline & 3.3 Outreach by engagement mechanism. \\
\hline \multirow[t]{3}{*}{ 4. Communication } & 4.1 Typology of communication mechanisms. \\
\hline & 4.2 Diversity of communication mechanisms. \\
\hline & 4.3 Outreach by communication mechanism. \\
\hline \multirow[t]{3}{*}{ 5. Building capacity } & 5.1 Participants' understanding of the planning process. \\
\hline & 5.2 Participant's awareness of urban planning key topics. \\
\hline & 5.3 Participants' assessment of the engagement process. \\
\hline \multirow[t]{3}{*}{ 6. Impact } & 6.1 Contributions to the plan (by urban planning key topics). \\
\hline & 6.2 Support \& consensus (by urban planning key topics). \\
\hline & 6.3 Incorporation of engagement contributions into the plan. \\
\hline
\end{tabular}

Mechanisms and communication, the third and fourth standards, focus on typology, diversity and outreach by engagement and communication mechanisms used in the process, the first organized by engagement levels. While mostly based on process outputs through quantitative indicators, they also allow for a qualitative analysis and assessment.

The last two standards relate to the process' outcomes in terms of building capacity (raising awareness and understanding of the plan) and impact (contributions, support and consensus by urban planning key topics). Although supported by quantitative indicators, the analysis of these two standards is mostly qualitative.

\section{CASE STUDY ANALYSIS}

4.1 Case study selection of engagement processes in municipal urban plans

The case study focuses in six engagement processes within municipal urban plans in the Basque Country, Navarre, and Cantabria, in the north of Spain.

1. Bilbao, Basque Country: Engagement in the Advance phase of the Municipal Urban Development Plan (MUDP) [17].

2. Santander, Cantabria: Public consultation previous to the MUDP [18].

3. Getxo, Basque Country: Engagement in the MUDP Advance phase [19].

4. Irun, Basque Country: Engagement in the Advance phase of the MUDP Modification in the railroad area (ViaIrun Master Plan) [20].

5. Zumaia, Basque Country: Engagement in the Information phase of the MUDP [21].

6. Cendea de Cizur, Navarre: Engagement in nine small towns within the municipality [22]. 
The selection of the case studies is due to five main reasons: similar planning scale (municipal-scale) and phase (plans' early stages), diversity in municipality's scale (with populations from 4,000 to 350,000), geographical proximity, first-hand information and COVID impact diversity (with both pre- and during-COVID experiences). The last case study, Cendea de Cizur, is the only one not directly related to a MUDP but to more specific urban design and infrastructure issues relevant for a municipal urban strategy. It is included because of its smaller scale to provide empirical data, as it is a 4,000-inhabitant municipality consisting, at the same time, of nine smaller towns ranging from 60 to 3,000 residents.

\subsection{Main results from the comparative study}

\subsubsection{Scope}

All six case studies target and achieve the same level of engagement, consensus building, all including the previous levels of information and consultation. While all go far beyond the minimum legal requirements for engagement in urban planning in the Basque Country, none attain the highest-intensity level of decision-making and empowerment.

In terms of process planning, the case studies relate to the plans' early stages; be it at the earliest phase (Santander, Zumaia, C. de Cizur) or at the Advance Phase, prior to the plan's Initial Approval (Bilbao, Getxo, Irun). The first approach is useful in providing first -hand initial information to later develop alternatives and proposals. In turn, the second approach is useful to contrast and complement the plans' first proposals, before the Criteria and Objectives document and the development of the Initial Approval document.

As for process structure by urban planning topics, the five MUDP case studies include the six topics directly related to urban planning land-uses: housing, mobility, public space, economic activity, facilities and services, and landscape and natural environment. Urban regeneration, which is gaining momentum in Europe, is incorporated either on its own or within housing or patrimony. The largest cities and towns (Bilbao, Santander, Getxo, Irun) also include a first topic on regional and urban strategy. All case studies comprise crosscutting topics, such as patrimony, inclusion (including gender, age-diversity and safety), and sustainability and climate change. A few also cover innovation (with caveats about what it really entails in urban planning) and the most recent case includes health, whose relationship to urban form has been argued for years, becoming increasingly relevant with the pandemic.

\subsubsection{Inclusion}

Case studies target mostly to local residents. Stakeholder typologies are completed by local associations, people working or studying in the municipality, as well as visiting. To a lower extent, municipal technicians and politicians. Santander and Zumaia adapted their stakeholder typology to include occasional residents (week-ends and holidays).

Comparing quantity of participants relative to population (number of participants per 1,000 residents), instead of by absolute values, suggests a potential relationship with scale (Fig. 1). Results show a tendency of higher participation in lower population towns (dashed line) with a spike in the less populated case study. While this may be useful to avoid false expectations, other factors are obviously key for attaining a higher number of participants, such as communication and engagement mechanisms, and further research with more empirical data needs to be conducted to affirm a relationship between scale and quantity of people engaged. 


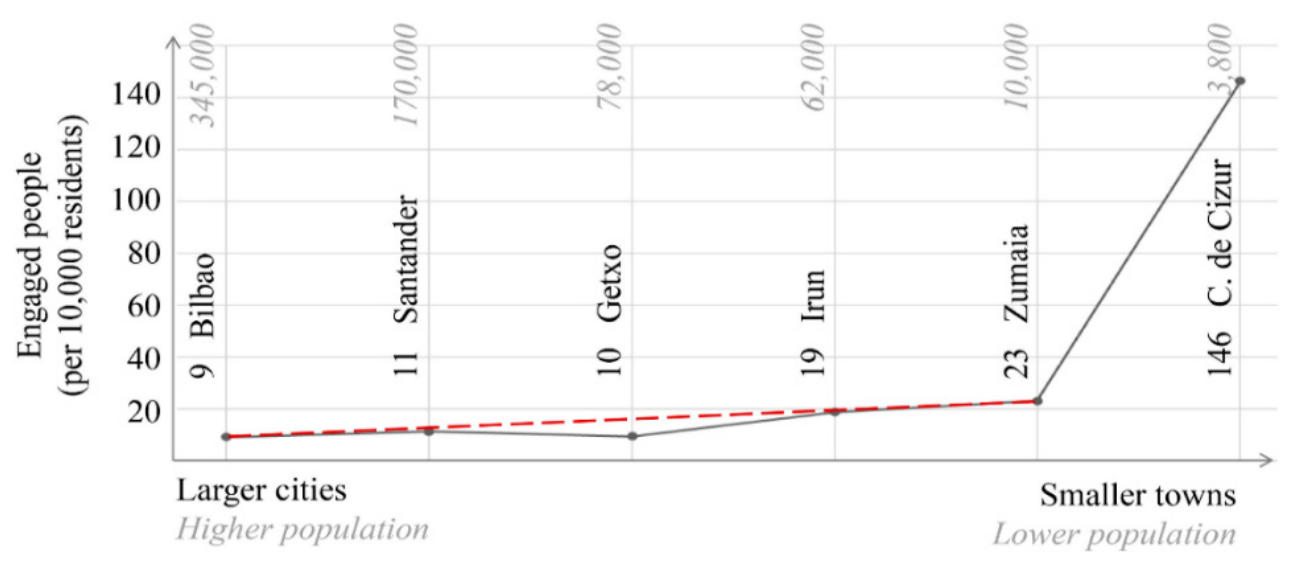

Figure 1: Quantity of participants: engaged people per 10,000 residents.

Looking at diversity by gender (Fig. 2), results show an overall higher participation of men than women in the largest cities (Bilbao, Santander, Getxo and Irun). The pattern shifts in the smaller towns of Zumaia and C. de Cizur, with women participating in a very similar percentage as in the overall population (around 50-52\% being women). Looking at specific engagement mechanisms, on average, face to face events gather more men than women, suggesting the need to overcome this. At the same time, digital consultation usually provides a more even participation between men and women. This could explain the shift in gender equality in Zumaia, where, due to the pandemic, engagement was mostly digital and by interviews, whereas in the other case studies, face-to face meetings and sessions had a higher relevance. Further research could be developed in terms of culture and politics, and its impact or reflection in women's roles and expectations, arguing Santander, Getxo and Bilbao are more conservative, and Zumaia and the smaller towns within C. de Cizur more progressive.

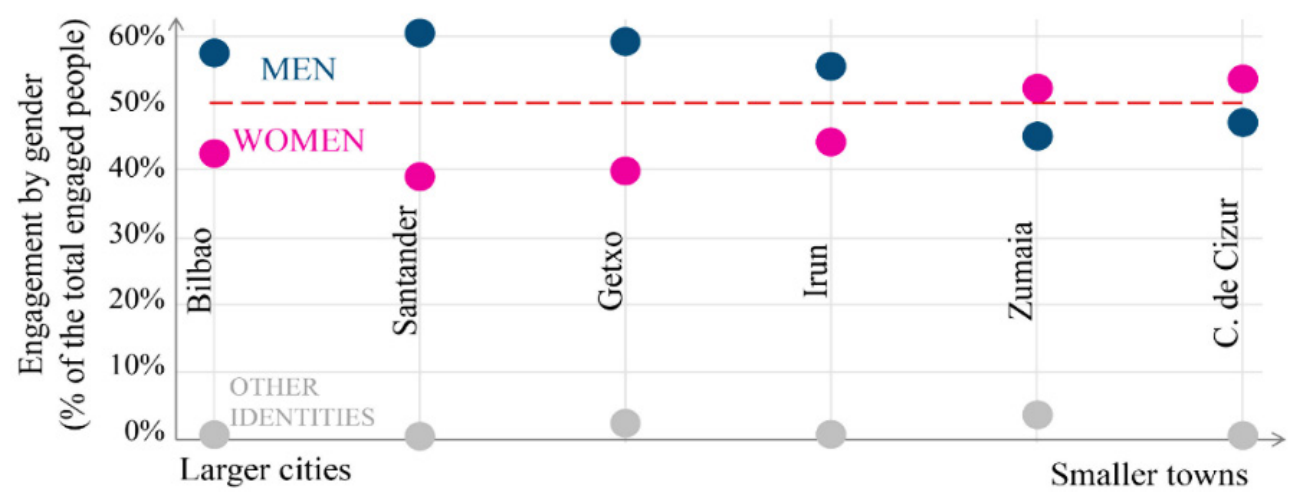

Figure 2: Diversity of participants by gender. 


\subsubsection{Mechanisms}

All six case studies include informative, consultive and consensus building engagement mechanisms, combining them in different ways, as reflected in Table 3. The pandemic, affecting the processes in Zumaia and Santander required significant adaptation; delaying, suspending or adapting in person means (depending of the specific health situation at the moment). Zumaia, specifically, had to basically rely on digital consultation and interviews.

Table 3: Typology and diversity of engagement mechanisms by level of engagement (Standard 3, Indicators 3.1 and 3.2 in Table 2).

\begin{tabular}{|l|c|c|c|c|c|c|}
\hline Information mechanisms & B & S & G & I & Z & CC \\
\hline Website & & & & & & \\
\hline Informative brochures/leaflets & & & & & & \\
\hline Informative videos & & & & & & \\
\hline Informative lectures & & & & & & \\
\hline Exhibitions & & & & & & \\
\hline Individual informative meetings & B & S & G & I & Z & CC \\
\hline Consultation mechanisms & & & & & & \\
\hline Digital consultation & & & & & & \\
\hline Paper consultation & & & & & & \\
\hline Telephone interviews & & & & & & \\
\hline In person interviews & B & S & G & I & Z & CC \\
\hline Consensus building mechanisms & & & & & & \\
\hline Sessions/workshops with neighbours & & & & & & \\
\hline Focus sessions (experts/by topics) & & & & & & \\
\hline Sessions with children/youth & & & & & & \\
\hline Urban walks/citizen walks & & & & & & \\
\hline Advisory Committee & & & & & \\
\hline
\end{tabular}

In overall, results suggest the combination of different mechanisms is needed to achieve diversity. Particularly, the larger the target population, the higher diversity of mechanisms. Digital consultation generally gathers the highest number of participants and an even participation among men and women. While not building consensus per se, it is very useful to visualize consensus among participants. Paper consultation and interviews increase the diversity, despite being time-consuming. As for consensus building mechanisms, specifically when working in groups with collaborative design methods, they generally gather less people but are more effective in building awareness, understanding, trust and consensus, and in gathering more in-depth contributions to the plans. Focus sessions allow for specific views by topics and specific stakeholders, while sessions with children and youth in schools and universities are an effective way to alter the otherwise common gaussian curve in engagement by age. In this sense engaging people over 65 , remains a challenge.

\subsubsection{Communication}

Communication is key to reach out to the public. While websites are a minimum, more active means such as municipal magazines/newspapers and continuous press releases and posts in social media show spikes in number of participants in digital consultation. Continuous communication is most relevant, the larger the target population is. Bilbao and 
Santander, for instance, offered several press releases throughout the processes, with an impact of over 130 and 100 media appearances each. In turn, the smaller town of C. de Cizur, where the only communication means were WhatsApp and informative brochures distributed to every household, resulted in the highest quantity of participants per capita, by far (Fig. 1). In terms of social media, while some projects developed their own profiles, other used the municipality's, with similar or even better results, as these already have a set of followers.

\subsubsection{Building capacity}

Case study results confirm an increase in understanding and awareness of the planning process. According to the participants' assessment (undertaken in all pre-COVID cases), the majority affirms the process increased their understanding of the process. With slight differences within the case studies, the urban planning topics that arouse the highest awareness and interest among participants are, in general: mobility, housing and the natural environment, followed by public space, facilities and patrimony (Table 4, darker colours).

Table 4: Awareness, contribution and consensus by planning topics (Standards 5 and 6).

\begin{tabular}{|c|c|c|c|c|}
\hline & Urban planning key topics & $\begin{array}{c}\text { Awareness } \\
\text { (Ind. 5.2) }\end{array}$ & $\begin{array}{l}\text { Contrib. } \\
\text { (Ind. 6.1) }\end{array}$ & $\begin{array}{c}\text { Consensus } \\
\text { (Ind. 6.2) }\end{array}$ \\
\hline & Regional and urban strategy & 1 & 3 & 2 \\
\hline \multirow{3}{*}{ 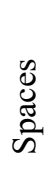 } & Landscape and natural environment & 3 & 3 & 4 \\
\hline & Mobility & 5 & 5 & 3 \\
\hline & Public space & 2 & 4 & 3 \\
\hline \multirow{3}{*}{ 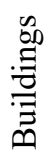 } & Housing & 4 & 3 & 1 \\
\hline & Economic activity & 1 & 2 & 2 \\
\hline & Facilities and services & 2 & 4 & 3 \\
\hline \multirow{5}{*}{ 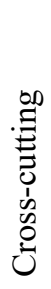 } & Urban regeneration & 1 & 1 & 3 \\
\hline & Patrimony & 2 & 3 & 3 \\
\hline & Inclusion & 1 & 2 & 4 \\
\hline & Sustainability and climate change & 1 & 2 & 5 \\
\hline & Innovation & 1 & 1 & 3 \\
\hline
\end{tabular}

\subsubsection{Impact}

All case studies gathered contributions from all urban planning topics, although topics that collected a higher number of contributions were generally mobility, public space and facilities (Table 4, darker colours). Of course, quantity does not mean quality. Processes mixed closed-ended questions to validate specific items or proposals (expressing results in consensus bars) together with open-ended questions, at times using collaborative maps.

Results reveal, in general, higher consensus and support in sustainability and climate change, followed by natural environment and inclusion. The topic that usually includes a higher diversity of opinions (hence, lower consensus) is in all cases housing (except C. de Cizur, where it didn't apply). It is followed by economic activity and, to a lower extent, 
regional and urban strategy. In all, results suggest citizens tend to agree more around crosscutting topics (sustainability and climate change, inclusion, patrimony) and space (be it for nature, mobility or public space). In turn, they tend to agree less when it comes to buildings, particularly housing (the largest share of buildings in Municipal Urban Development Plans).

\section{CONCLUSIONS}

The evaluative framework developed from the analysis of international models, together with its application to the case studies presented, allows for a better understanding of different considerations, outputs and outcomes related to the success or achievement of a given urban planning-related engagement process. The research lies within the consensus building level, as none of the cases attain higher, more ambitious citizen empowerment levels. Further research in the development of the framework needs to overcome challenges in obtaining some of the indicators (i.e. the incorporation of engagement contributions into the plan). At the same time, there are external factors that influence the processes, such as legislation, political will, economic resources, participatory culture, and, potentially, a municipality's scale. Additionally, despite a clear scope and planning, processes require adaptability to unforeseen circumstances such as the pandemic.

Nonetheless, the framework and comparative study attempt to go beyond demonstrating the different cities' commitment to public engagement, to provide empirical data and suggest similarities, variations and tendencies within the analysed case studies. This expects to be useful and transferable to future urban planning-related engagement processes. Among others, in order to overcome initial preconceptions, avoid false expectations and better design and undertake them, considering the targeted level of engagement, quantity and diversity of participants, engagement and communication mechanisms and outcomes in terms of building citizen capacity and impact and contribution to the plan. In all, to foster a more inclusive urbanism, with a higher social impact and enriched by citizen contribution.

\section{REFERENCES}

[1] Rosenzweigov, I., Skoric, V., Hadzi-Miceca, K. \& Asipovich, H., Civil Participation in Decision-Making Processes: An Overview of Standards and Practices in Council of Europe Member States, European Center for Not-for-profit Law (ECNL), 2016.

[2] Horgan, D. \& Dimitrijevic, B., Frameworks for citizens participation in planning: From conversational to smart tools. Sustainable Cities and Society, 48, 101550, 2019. DOI: $10.1016 /$ j.scs.2019.101550.

[3] Hanover Research, Public Engagement Strategies and Evaluation, 2014.

[4] Niemi, R., Sustar, H. \& Kokkonen, A., The levels of citizen engagement in urban development. The Value of Design Research, 11th European Academy of Design Conference, 2015.

[5] Hussey, S., International public participation models 1969-2020. www.bangthetable.com/blog/international-public-participation-models/. Accessed on: 21 Apr. 2021.

[6] Arnstein, S., A ladder of citizen participation. Journal of the American Planning Association, 34(4), pp. 216-224, 1969.

[7] Karsten, A., Participation Models: Citizens, Youth, Online. A Chase Through the Maze, Creative Commons, 2012.

[8] UN-Habitat, Inclusive and Sustainable Urban Development Planning: A Guide for Municipalities, vol. 1, 2007. 
[9] International Association for Public Participation (IAP2), The three pillars of public participation. www.iap2.org/page/pillars. Accessed on: 23 Apr. 2021.

[10] Atlee, T. et al., Core Principles for Public Engagement, National Coalition for Dialogue \& Deliberation (NCDD), 2009.

[11] Macdonald, B., Rust, C., Thrift, C. \& Swanson, D., Measuring the Performance and Impact of Community Indicators Systems: Insights on Frameworks and Examples of Key Performance Indicators, International Institute for Sustainable Development, 2012.

[12] Parés, M. \& Mar., H., Guide to Evaluating Participatory Processes, International Observatory on Participatory Democracy (IOPD), 2013.

[13] Scottish Government, National Standards for Community Engagement, 2016.

[14] Architecture \& Design Scotland, NHS Health Scotland, Scottish Government, Place Standard, 2017.

[15] Open Government Partnership (OGP), Participation \& Co-Creation Standards, 2017.

[16] Bedson, J. \& Abramowitz, S., Minimum Quality Standards and Indicators for Community Engagement, UNICEF, 2019.

[17] City of Bilbao, Memoria Final de la Ejecución del Plan de Participación Ciudadana, Avance del Plan General de Ordenación Urbana de Bilbao, 2017.

[18] City of Santander, Memoria y Conclusiones. Consulta Pública Ciudadana Previa a la Revisión del Plan General de Ordenación Urbana de Santander, 2020.

[19] Municipality of Getxo, Informe del Proceso de Participación Ciudadana, Fase 3 participación ciudadana sobre el contenido del avance y adopción de criterios y objetivos, plan general de ordenación Urbana (PGOU) de getxo. 2018.

[20] City of Irun, Informe del Proceso de Participación Ciudadana, Avance de la Modificación Puntual del Plan General en el espacio ferroviario de Irun, 2019.

[21] Municipality of Zumaia, Anexo III. Informe del Proceso de Participación Ciudadana, Fase de Información del Plan General de Ordenación Urbana (PGOU) de Zumaia, 2020.

[22] Muncipality of Cendea de Cizur, Memoria de Resultados y Aportaciones, Procesos de participación ciudadana en los pueblos de la Cendea de Cizur, 2020. 